\title{
The results of applied research for solutions to environmental problems, expected!
}

\author{
Dolly Priatna and Kathryn A. Monk (Eds.)
}

With this issue, the Indonesia Journal of Applied Environmental Studies (InJAST) enters its second year, having been first published in April 2020 just as the Covid-19 pandemic was spreading globally. In the first two issues, InJAST published 13 articles, which were the results of research and ideas from academia, researchers from the Indonesian Institute of Sciences (LIPI) and members of conservation NGOs. Within its first year, the InJAST website has been visited by around 1,500 visitors from 50+ countries. Although the majority were from Indonesia, 30\% were from across Europe, Asia, the Americas, and Africa, and included the USA, UK, Australia, and India.

One of InJAST's missions is to provide a vehicle for academia (students and lecturers), members of environmental NGOs, and young researchers, particularly from Indonesia, who are just starting to publish their ideas, literature reviews and research findings or articles in scientific journals. InJAST was also developed to accommodate scientific papers related to broader environmental topics, but as yet, most articles have focused on plant/wildlife ecology, nature conservation, and forest restoration $(61 \%)$. Others were the result of the studies on environmental education $(8 \%)$ and on the UN Sustainable Development Goals (SDGs) and other environmental issues $(31 \%)$.

As we start the third decade of the 21 st century, the environmental challenges we face are ever more complex and demanding. The UN's global action plan for the next 10 years set out in the "UN's 2030 Agenda for Sustainable Development", puts forward special measures to achieve a world that is fairer, more prosperous, and more respectful of the environment. The main global environmental challenges that, according to the UN, must be resolved in this decade, are climate change mitigation and adaptation, pollution problems and their effects on health, protecting oceans, the energy transitions and renewables, a sustainable food model, protecting biodiversity, sustainable urban development and mobility, hydric stress and water scarcity, extreme meteorological phenomena, and overpopulation and waste management. As academics, environmental researchers, and members of environmental NGOs, we can and should support the UN agenda by seeking the solutions to these major global environmental problems that affect all of us. We do this by carrying out relevant research and, just as importantly, publishing them in scientific journals so that we can disseminate our findings as widely as possible and suggested interventions can be trialed and then implemented on the ground.

This new issue of InJAST contains several papers focusing on plant ecology, endangered species conservation, and forest restoration, all of which are closely related to one of the main global problems identified by the UN, namely protecting biodiversity. Another paper analyses determinants and typology of hydrometeorological disasters that may relate to the problem of extreme meteorological phenomena. Strong pro-environmental legislation and government regulations are very important in implementing existing environmental policies, and environmental awareness and responsibility are also important to assess whether people are willing to participate in addressing global environmental problems at the local level. This is explored in two other papers in this issue of InJAST.

We reflect further that we are in a hugely different place from where we were at the start of 2020. The Covid pandemic, obviously a global tragedy, has changed many people's behavioral patterns and our subsequent impact of nature and the environment. It seems to have in many ways heightened people's awareness of nature and environmental issues, and the relationships between unsustainable production and consumption and the nature and climate change crises. A plethora of new research is emerging on these interdisciplinary questions and we look forward to submissions tackling these questions in future editions of InJAST.

Finally, as Editors-in-Chief, we have been working hard to improve and expand our peer review community, as well as the processes of online submission, reviewing and publishing. We are delighted to be presenting Volume 2 No 1 of InJAST and we encourage our colleagues from all sectors to submit their papers for the next issue. 
InJAST's website and online submission portal is:

https://journal.unpak.ac.id/index.php/InJAST/index

Submissions can also be directed to the Chief Editors at: injast@unpak.ac.id

Comments on InJAST's website, reporting portal issues and other issues, should be addressed to the Editorial Manager at: editor_injast@unpak.ac.id

\section{NOTES}

\section{Lithium-ion batteries towards circular} economy: A literature review of opportunities and issues of recycling treatments

Nowadays, Lithium-ion batteries are widely used in advanced technological devices and Electric and Hybrid Vehicles, due to their high energy density for weight, reduced memory effect and significant number of supported charging/discharging cycles. As a consequence, the production and the use of Lithium-ion batteries will continuously increase in the near future, focusing the global attention on their End-of-Life management. Unfortunately, wasted Lithium-ion batteries treatments are still under development, far from the optimization of recycling processes and technologies, and currently recycling represents the only alternative for the social, economic and environmental sustainability of this market, able to minimize toxicity of End-of-Life products, to create a monetary gain and to lead to the independence from foreign resources or critical materials. This paper analyses the current alternatives for the recycling of Lithium-ion batteries, specifically focusing on available procedures for batteries securing and discharging, mechanical pre-treatments and materials recovery processes (i.e. pyro- and hydrometallurgical), and it highlights the pros and cons of treatments in terms of energy consumption, recovery efficiency and safety issues. Target metals (e.g. Cobalt, Nickel and Lithium) are listed and prioritized, and the economic advantage deriving by the material recovery is outlined. An in-depth literature review was conducted, analysing the existing industrial processes, to show the on-going technological solutions proposed by research projects and industrial developments, comparing best results and open issues and criticalities.

Mossali et al. (2020). Lithium-ion batteries towards circular economy: A literature review of opportunities and issues of recycling treatments. Fournal of Environmental Management 264:1 10500.

\section{Challenges and practices on waste management and disposal during GOVID-19 pandemic}

The COVID-19 pandemic has imposed a global emergency and also has raised issues with waste management practices. This study emphasized the challenges of increased waste disposal during the COVID-19 crisis and its response practices. Data obtained from the scientific research papers, publications from the governments and multilateral organizations, and media reports were used to quantify the effect of the pandemic towards waste generation. A huge increase in the amount of used personal protective equipment (facemasks, gloves, and other protective stuffs) and wide distribution of infectious wastes from hospitals, health care facilities, and quarantined households was found. The amount of food and plastic waste also increased during the pandemic. These factors caused waste treatment facilities to be overwhelmed, forcing emergency treatment and disposals (e.g., co-disposal in a municipal solid waste incinerator, cement kilns, industrial furnaces, and deep burial) to ramp up processing capacity. This paper discussed the ways the operation of those facilities must be improved to cope with the challenge of handling medical waste, as well as working around the restrictions imposed due to COVID-19. The study also highlights the need for short, mid, and longer-term responses towards waste management during the pandemic. Furthermore, the practices discussed in this paper may provide an option for alternative approaches and development of sustainable strategies for mitigating similar pandemics in the future.

Hantoko et al. (2021) Challenges and practices on waste management and disposal during COVID-19 pandemic. Fournal of Environmental Management 286:112140.

\section{A study of consumer behaviour towards food-waste in Ireland: Attitudes, quantities and global warming potentials}

This study aimed to investigate consumer behaviour towards food waste in Ireland by analysing their attitudes and quantities of food waste generated. Global warming potential of the food waste generated weekly is then assessed. A total of 2115 participants from all over the Republic of Ireland contributed to the survey (of which 2062 were included in this research). Using factor and cluster analysis, two clusters of consumers were formed based on their attitudes towards food waste, and it was found that $62.56 \%$ of the sample were 'uncaring' consumers and $37.44 \%$ 
were 'caring' consumers. The uncaring consumers consisted of more young males and were relatively unphased by food waste and take minimal precautions to reduce food waste at all stages of consumption. In contrast, caring consumers consisted of older and female consumers and were deeply disturbed by food waste, taking all precautions to reduce food waste at every stage of consumption. Regarding food waste quantities, uncaring consumers produced on average, $0.74 \mathrm{~kg}$ of food waste weekly, accounting for $2.74 \mathrm{~kg}$ of $\mathrm{CO}_{2}$ equivalent in global warming potential, whereas caring consumers produced only half this amount. Our results thus suggest that consumers attitudes towards food waste directly impact the food waste quantities they generate and consequently the global warming effects. However, in Ireland all consumer groups can benefit from more information about food waste and our study contributes by providing information that can inform strategic communication campaigns at policy or organisational level, to educates consumers about food waste and how they are contributing to global warming.

Flanagan \& Priyadarshini (2021). A study of consumer behaviour towards food-waste in Ireland: Attitudes, quantities and global warming potentials. Journal of Environmental Management 284: 112046.

\section{Recent developments in Life Cycle Assessment}

Life Cycle Assessment is a tool to assess the environmental impacts and resources used throughout a product's life cycle, i.e., from raw material acquisition, via production and use phases, to waste management. The methodological development in LCA has been strong, and LCA is broadly applied in practice. The aim of this paper is to provide a review of recent developments of LCA methods. The focus is on some areas where there has been an intense methodological development during the last years. We also highlight some of the emerging issues. In relation to the Goal and Scope definition we especially discuss the distinction between attributional and consequential LCA. For the Inventory Analysis, this distinction is relevant when discussing system boundaries, data collection, and allocation. Also highlighted are developments concerning databases and Input-Output and hybrid LCA. In the sections on Life Cycle Impact Assessment we discuss the characteristics of the modelling as well as some recent developments for specific impact categories and weighting. In relation to the Interpretation the focus is on uncertainty analysis. Finally, we discuss recent developments in relation to some of the strengths and weaknesses of LCA.

Finnveden et al. (2009). Recent developments in Life Cycle Assessment. Journal of Environmental Management 91:1-21.

\section{Environmental sustainability of anaerobic digestion of household food waste}

Consumers are the leading producers of food waste (FW) in developed countries and the majority of household FW is still embedded in general waste where it is incinerated or landfilled. There is increasing awareness in the value of collecting FW as a separate waste stream for production of compost or recovery of energy through anaerobic digestion (AD). This study focuses on $\mathrm{AD}$ to evaluate the life cycle environmental sustainability of recovering energy and fertilisers from household FW in the UK. The analysis is carried out for two different functional units: i) treatment of 1 tonne of FW, which is compared to incineration and landfilling; and ii) generation of $1 \mathrm{MWh}$ of electricity, which is compared to other electricity generation options. The former results in net negative greenhouse gas (GHG) emissions (-39 kg $\mathrm{CO}_{2}$-eq./t) and primary energy demand $(-2 \mathrm{GJ} / \mathrm{t})$ due to the displacement of grid electricity and mineral fertilisers. AD has lower impacts than both incineration and landfilling across 15 of the 19 impacts. However, the application of digestate to land and the release of ammonia and nitrates lead to higher marine eutrophication (ME), terrestrial acidification (TA) and particulate matter formation $(\mathrm{PMF})$. For the second functional unit, AD electricity emits $203 \mathrm{~kg} \mathrm{CO}_{2}$-eq./MWh, compared to $357 \mathrm{~kg} \mathrm{CO}_{2}$-eq./MWh for the UK grid mix. Compared to renewables, such as wind and solar, AD electricity has lower energy demand, toxicity potentials and metal depletion. However, it has higher global warming potential, ME, TA and PMF. At the UK level, treating $4.9 \mathrm{Mt}$ of kerbside FW collected annually could provide $0.37 \%$ of the national electricity demand and save $190,000 \mathrm{t} \mathrm{CO}_{2}$-eq./yr compared to the grid electricity. The digestate produced could displace $1 \%$ of industrial nitrogen fertilisers. Although small fractions of the national demands, they represent a valuable return from a largely unutilised waste stream and help towards implementation of a circular economy.

Slorach et al. (2019). Environmental sustainability of anaerobic digestion of household food waste. Fournal of Environmental Management 236:798-814.

\section{Sustainable construction-The role of environmental assessment tools}

Construction has been accused of causing environmental problems ranging from excessive consumption of global resources both in terms of construction and building operation to the pollution of the surrounding environment, and research on green building design and using building materials to minimise environmental impact is already underway. However, relying on the design of a project to achieve the goal of sustainable development, or to minimise 
impacts through appropriate management on site, is not sufficient to handle the current problem. The aim for sustainability assessment goes even further than at the design stage of a project to consider its importance at an early stage, before any detailed design or even before a commitment is made to go ahead with a development. However, little or no concern has been given to the importance of selecting more environmentally friendly designs during the project appraisal stage; the stage when environmental matters are best incorporated. The main objectives of this paper are to examine the development, role and limitations of current environmental building assessment methods in ascertaining building sustainability used in different countries which leads to discuss the concept of developing a. sustainability model for project appraisal based on a multi-dimensional approach, that will allow alternatives to be ranked is discussed in detail in the paper.

Ding (2008). Sustainable construction - The role of environmental assessment tools. Fournal of Environmental Management 86 (3):45 1-464.

\section{The impact of COVID 19 on air pollution levels and other environmental indicators - A case study of Egypt}

The outbreak of coronavirus disease (COVID-19) not only affected health and economics, but also its effect extended to include other aspects, such as the environment. Using Egypt as a case study, this paper presents the impact of COVID-19 pandemic on air pollution levels by studying nitrogen dioxide $\left(\mathrm{NO}_{2}\right)$, ozone $\left(\mathrm{O}_{3}\right)$, particulate matter represented in absorbing aerosol index (AAI), carbon monoxide (CO), and greenhouse gas $(\mathrm{GHG})$ emissions. The paper also highlights the impact of COVID-19 pandemic on other environmental indicators including environmental noise, medical and municipal solid wastes. The paper presents the Egyptian COVID-19 story from its different angles including the development of confirmed COVID-19 cases, containment measures from the government, the impact on the country's economy and the national energy consumption so as to effectively evaluate the effect on both the air pollution levels and the other studied environmental indicators. For the other environmental indicators, a strong link was observed between COVID-19 lockdown and the reduction in environmental noise, beaches, surface and groundwater pollution. For environmental noise, this has been confirmed by officially governmental announcements which reported that the level of environmental noise in Egypt was reduced by about $75 \%$ during the lockdown period. On the other hand, there are some negative effects, including an increase in medical solid waste (from 70 to 300 ton/day), municipal solid waste, as well as a less efficient solid waste recycling process. For air pollution levels, the data were obtained from National Aeronautics and Space Administration (NASA) and European Space Agency satellite data sets. The data for the lockdown period in 2020 have been extracted and compared to the corresponding months in the selected baseline period (2015-2019) to identify the effect that the lockdown period had on the air pollution levels in Egypt with focus on Cairo and Alexandria governorates. It was found that the AAI decreased by about $30 \%$, the NO2 decreased by 15 and 33\% over Cairo and Alexandria governorates, respectively, and that the $\mathrm{CO}$ decreased by about $5 \%$ over both governorates. In addition, the GHG emissions in Egypt were reduced by at least $4 \%$ during the pandemic. In contrast, ozone levels increased by about 2\% over Cairo and Alexandria governorates. It can be concluded that the implemented containment measures during COVID-19 pandemic had resulted in both positive and negative environmental impacts. The positive environmental impacts are not sustainable and deterioration on them is expected to occur after the lockdown as it was before the pandemic. Therefore, stricter laws must be enacted to protect the environment in Egypt.

Mostafa et al. (2021). The impact of COVID 19 on air pollution levels and other environmental indicators - A case study of Egypt. Journal of Environmental Management 277:111496.

\section{Enhancing domestic water conservation behaviour: A review of empirical studies on influencing tactics}

The world faces imminent drought-related challenges that, from a tap-water supply perspective, require increasingly expensive infrastructure enhancement and energy expansion to maintain sufficient service levels. This paper argues that enhancing domestic water conservation provides a promising alternative or necessary addition to reduce costs and to stimulate pro-environmental behaviour. Although the number of field experiments on how people's behaviour can be changed with respect to their daily water consumption is growing, to date, most studies in this field have focussed either on explanatory socio-economic factors (e.g. water pricing, income, or family composition) or behavioural intentions and personal characteristics related to behavioural change. Accordingly, there is limited empirically validated knowledge about the use and effectiveness of different influencing tactics to change behaviour. This paper provides a review of the empirically oriented literature in this field and aims to provide an up-to-date assessment that identifies eight different Behavioural 
Influencing Tactics (BITs) that target long-term water conservation behaviour within households. Our analysis is structured around three information processing routes: the reflective route, the semi-reflective route, and the automatic route. We conclude that the current body of literature is promising and provides a useful body of evidence on the range and effectiveness of individual water conservation mechanisms, but that needs further development to deepen our understanding of how to effectively prolong and reinforce newly formed water conservation routines.

Koop et al. (2019). Enhancing domestic water conservation behaviour: A review of empirical studies on influencing tactics. Fournal of Environmental Management 247:867-876.

\section{Biological approaches to tackle heavy metal pollution: A survey of literature (Review)}

Pollution by heavy metals has been identified as a global threat since the inception of industrial revolution. Heavy metal contamination induces serious health and environmental hazards due to its toxic nature. Remediation of heavy metals by conventional methods is uneconomical and generates a large quantity of secondary wastes. On the other hand, biological agents such as plants, microorganisms etc. offer easy and eco-friendly ways for metal removal; hence, considered as efficient and alternative tools for metal removal. Bioremediation involves adsorption, reduction or removal of contaminants from the environment through biological resources (both microorganisms and plants). The heavy metal remediation properties of microorganisms stem from their self defense mechanisms such as enzyme secretion, cellular morphological changes etc. These defence mechanisms comprise the active involvement of microbial enzymes such as oxidoreductases, oxygenases etc, which influence the rates of bioremediation. Further, immobilization techniques are improving the practice at industrial scales. This article summarizes the various strategies inherent in the biological sorption and remediation of heavy metals.

Jacob et al. (2018). Biological approaches to tackle heavy metal pollution: A survey of literature (Review). Journal of Environmental Management 217:56-70.

\section{Microalgae harvesting techniques: A review (Review)}

Microalgae with wide range of commercial applications have attracted a lot of attention of the researchers in the last few decades. However, microalgae utilization is not economically sustainable due to high cost of harvesting. A wide range of solid liquid separation techniques are available for microalgae harvesting. The techniques include coagulation and flocculation, flotation, centrifugation and filtration or a combination of various techniques. Despite the importance of harvesting to the economics and energy balance, there is no universal harvesting technique for microalgae. Therefore, this review focuses on assessing technical, economical and application potential of various harvesting techniques so as to allow selection of an appropriate technology for cost effectively harvesting of microalgae from their culture medium. Various harvesting and concentrating techniques of microalgae were reviewed to suggest order of suitability of the techniques for four main microalgae applications i.e biofuel, human and animal food, high valued products, and water quality restoration. For deciding the order of suitability, a comparative analysis of various harvesting techniques based on the six common criterions (i.e biomass quality, cost, biomass quantity, processing time, species specific and toxicity) has been done. Based on the order of various techniques vis-a-vis various criteria and preferred order of criteria for various applications, order of suitability of harvesting techniques for various applications has been decided. Among various harvesting techniques, coagulation and flocculation, centrifugation and filtration were found to be most suitable for considered applications. These techniques may be used alone or in combination for increasing the harvesting efficiency.

Sing \& Patidar (2018). Microalgae harvesting techniques: A review (Review). Journal of Environmental Management 217:499-508.

\section{EVENTS}

\section{Towards a New Era of Natural Resources and Environmental Management. The $2^{\text {nd }}$ \\ International Seminar on Natural Resources and Environmental Management (ISeNREM) 2021 (4-5 August 2021, Online)}

Natural Resources and Environmental Management Science (NREMS) Study Program, Graduate School of IPB University will hold an international scientific seminar in environmental science, namely "The 2nd International Seminar on Natural Resources and Environmental Management 2021" or ISeNREM 2021. The NREMS successfully conducted the 1 st ISeNREM in 2019. This activity is a seminar which is expected to be a "kick off" event for the exchange of scientific information from various scientific disciplines between experts from many countries in the field of environment in a broad sense, as well as creating networks and collaborations in further research in efforts to find solutions to environmental problems. In addition, as an event to increase the possibility for 
young researchers to conduct independent research in their home countries in the future.

https://isenrem.ipb.ac.id/

\section{The $6^{\text {th }}$ INAFOR 2021 - Greener Future: \\ Environment, Disaster Resilience, and Climate Change (7-8 September 2021)}

INAFOR - International Conference of Indonesia Forestry Researchers is the global network for Forests and also environment scientist. It unities more than 2,500 scientists in almost 50 organizations on over 20 countries. Scientists cooperate in INAFOR on a voluntary basis. This is a promising space for sharing research, building awareness also generating network throughout the world, crossing oceans and mountains, beyond those boundaries. The $6^{\text {th }}$ INAFOR 2021 will stream on forest and environment management while supporting Sustainable Development Goals-SDGs, thereby, the general theme may has "Greener Future: Environment, Disaster Resilience, and Climate Change". It is also an opportunity to promote the Indonesian's and other countries' work on improving environment on the ground, and to showcase success at the implementation, put sciences is in place. Pandemic COVID-19 is now become a global challenge to generate efforts for survive. The critical given that forests and environments, also broader landscapes are important to stakeholders giving efforts to achieve their SDGs targets.

http://inafor.forda-mof.org/

\section{The UK will host the $26^{\text {th }}$ UN Glimate Change Conference of the Parties (COP26) in Glasgow on 1 - 12 November 2021.}

The GOP26 UN climate change conference set to take place in Glasgow in November 2020 has been postponed due to COVID-19. This decision has been taken by the COP Bureau of the UNFGGG (United Nations Framework Convention on Climate Change), with the UK and its Italian partners. Dates for a rescheduled conference in 2021, hosted in Glasgow by the UK in partnership with Italy, have been set to 1-12 November 2021. In light of the ongoing, worldwide effects of COVID-19, holding an ambitious, inclusive COP26 in November 2020 was no longer possible. Rescheduling will ensure all parties can focus on the issues to be discussed at this vital conference and allow more time for the necessary preparations to take place. We will continue to work with all involved to increase climate ambition, build resilience and lower emissions. https://unfccc.int/process-and-meetings/conferences /glasgow-climate-change-conference
IUGN World Conservation Congress 2021: One Nature, One Future. Marseille, France, 3-11 September 2021.

Protected and conserved areas - a critical conservation tool. When managed effectively, protected and conserved areas are a critical tool for biodiversity conservation and for safeguarding ecosystem services. There are also many socioeconomic benefits that are reaped by local communities in and around these areas. The messages and reflections below from IUCN Members address various types of protected and conserved areas, share success stories, and emphasise initiatives such as the goal to protect $30 \%$ of land and oceans by 2030, which IUCN Members endorsed during an online vote at the end of last year. Managing landscapes for nature and people will be a major theme of the IUCN World Conservation Congress, with over 100 sessions focusing on protected and conserved areas. For further information and registration please visit https://civicrm.iucn.org/civicrm/mailing/view?reset $=1 \& \mathrm{id}=3053$

\section{$16^{\text {th }}$ International Peatland Congress 2021( 03 - 06 May 2021, Online from Tallinn)}

The format of the Congress will remain as planned. Alongside the scientific programme, the IPC2021 will include the Industry Summit, PEAT-talks, excursions and mid-congress fieldtrips, a student programme, exhibition and several social and networking events. The photo contest is up and running and you all have the opportunity to submit your work via the Congress website until the end of March 2021. The abstracts submitted for the 2020 Congress that have been accepted by the Scientific Committee will retain their status for the 2021 Congress. The authors will receive detailed instructions from the Congress Secretariat at the beginning of June in case the authors need to update their short or extended abstracts. The Scientific Committee of IPC2021 has also decided to open additional abstract submission in October 2020. This serves to give new authors the opportunity to present their work at the Congress. Exact guidelines will be published on the Congress website.

https://www.cifor.org/event/16th-international-peatl and-congress-2021/

\section{Nature-Based Solutions: How Restoration can Support a Healthy Glimate, Economy and Planet (29 April 2021, online)}

Over 40 percent of the world's population is affected by land degradation. Land degradation threatens food security, fuels violent conflict, drives biodiversity loss and contributes to the climate crisis through carbon and nitrous oxide emissions. It costs the global economy around USD 6-10 trillion per year, or roughly 10 percent of gross world product. One of the most promising solutions to land degradation is forest 
and landscape restoration (FLR), which aims to regain ecological functionality and enhance human well-being in deforested or degraded landscapes. More than 2 billion hectares of such landscapes stand to be restored globally. However, FLR implementation still remains far below the level needed to address land degradation on a global scale. On 29 April 2021, the Global Landscapes Forum will organize a digital forum on FLR hosted jointly by the Collaborative Partnership on Forests $(\mathrm{CPF})$ and the Global Partnership on Forest and
Landscape Restoration (GPFLR). This event will help increase understanding in three key areas where FLR can make significant contributions: climate mitigation and adaptation, job creation, and reducing threats to biodiversity. It will also provide an opportunity to showcase the role of partnerships and collaboration in successful FLR.

https://www.cifor.org/event/nature-based-solutions-h ow-restoration-can-support-a-healthy-climate-econom y-and-planet/ 